\title{
Utilização de espécies de Asteraceae por comunidades rurais do nordeste do Brasil: relatos em Camocim de São Félix, Pernambuco
}

\author{
Aryêcha Arruda da Silva * \\ Laise de Holanda Cavalcanti Andrade \\ Universidade Federal de Pernambuco \\ Avenida Prof. Moraes Rego, 1235, Cidade Universitária \\ CEP 50670-901, Recife - PE, Brasil \\ * Autor para correspondência \\ aryecha@hotmail.com
}

Submetido em 02/10/2012

Aceito para publicação em 28/02/2013

\section{Resumo}

Asteraceae, com aproximadamente 2.000 espécies registradas no Brasil, destaca-se nos estudos etnobotânicos, posicionando-se quase sempre entre as quatro famílias com maior número de espécies na flora útil, principalmente para fins medicinais. Neste estudo investigou-se a importância dessa família em quatro comunidades rurais do município de Camocim de São Félix, em um brejo de altitude, no agreste de Pernambuco. Os trabalhos de campo foram realizados no período de dezembro de 2010 a maio de 2011. Para a coleta dos dados etnobotânicos, foram realizadas entrevistas semiestruturadas com 50 moradores, de ambos os sexos, na maioria agricultores, com renda familiar inferior a um salário-mínimo, sendo coletadas as espécies por eles citadas. Os entrevistados mostraram um diversificado conhecimento sobre as Asteraceae, citando 19 espécies, nas seguintes categorias: medicinal (12), ornamental (6), tecnológica (3) e alimentícia (2), algumas delas incluídas em mais de uma categoria. Acanthospermum hispidum DC., espécie ruderal conhecida como espinho-de-cigano, foi a planta mais citada como medicinal, indicada para o tratamento de problemas respiratórios, infecções, doenças renais e odontalgias. As espécies Dahlia pinnata Cav., Tagetes erecta L. e Zinnia elegans Jacq. são utilizadas como ornamentais. Lactuca sativa L. (cultivada) e Emilia sonchifolia (L.) DC. (daninha) foram as únicas citadas como alimentícias e Conyza bonariensis (L.) Cronquist, Egletes viscosa Less. e Parthenium hysterophorus L. foram citadas para fins tecnológicos.

Palavras-chave: Acanthospermum hispidum; Brejo; Compositae; Etnobotânica

\section{Abstract}

Use of Asteraceae species by rural communities in Northeastern Brazil: reports in Camocim de Sao Felix, Pernambuco, Brazil. Asteraceae, with around 2,000 species registered in Brazil, stand out in the ethnobotanical studies, placing them almost always among the four families with the greatest number of species in the useful flora, especially for medicinal purposes. In this study, one investigated the importance of this family in four rural communities in the town of Camocim de Sao Felix, in an altitude swamp, in the agreste region of the State of Pernambuco, Brazil. The field works were conducted within the period from December 2010 to May 2011. For the collection of ethnobotanical data, semi-structured interviews were conducted with 50 inhabitants, 
of both sexes, most of them farmers, with family income less than one minimum wage, and there was collection of species cited by them. The respondents showed a varied knowledge on the Asteraceae, citing 19 species, in the following categories: medicinal (12), ornamental (6), technological (3), and alimentary (2), some of them included in more than one category. Acanthospermum hispidum DC., ruderal species know as bristly starbur, was the most frequently cited as medicinal plant, indicated for the treatment of respiratory problems, infections, kidney diseases, and toothaches. The species Dahlia pinnata Cav., Tagetes erecta L., and Zinnia elegans Jacq. are used as ornamental plants. Lactuce sativa L. (cultivated) and Emilia sonchifolia (L.) DC. (weed) were the only ones cited as alimentary and Conyza bonariensis (L.) Cronquist, Egletes viscosa Less., and Parthenium hysterophorus L. were cited for technological purposes.

Key words: Acanthospermum hispidum; Swamp; Compositae; Ethnobotany

\section{Introdução}

As Asteraceae (Dumortier) possuem distribuição cosmopolita e constituem a maior família de Eudicotiledôneas, com 1.620 gêneros e 23.600 espécies (STEVENS, 2012). Estima-se que cerca de metade das espécies ocorrem no Novo Mundo e no Brasil tem-se registros de aproximadamente 250 gêneros e 2.000 espécies, distribuídas em todo o território nacional (HIND, 1993; PEREIRA, 2001; SOUZA; LORENZI, 2008).

Podem ser ervas, subarbustos, arbustos, pequenas árvores ou lianas, com folhas alternas ou opostas, raramente verticiladas, simples, margem inteira ou serreada. As inflorescências são capítulos envolvidos por brácteas, formando um invólucro. As flores são todas iguais entre si, ou diferenciadas em flores do raio e flores do disco. As primeiras são altamente modificadas, podendo ser estéreis e possuir corola hipertrofiada, enquanto as flores do disco são bissexuadas ou raramente unissexuadas. O fruto é do tipo cipsela, com papilho geralmente persistente (SOUZA; LORENZI, 2008).

Do ponto de vista econômico, cerca de 40 espécies têm importância direta na alimentação humana, como alface e chicória, e indireta na obtenção de produtos, como girassol, camomila e carqueja. Espécies silvestres têm potencial nutricional, muitas são de interesse tecnológico ou ornamental, e centenas produzem metabólitos secundários de uso farmacêutico ou industrial ou fornecem néctar e pólen para a apicultura e também forragem para a produção pecuária (VITTO; PETENATTI, 2009).

A pesquisa etnobotânica, considerada como mediadora entre o discurso científico e o saber tradicional (SILVA et al., 2009), demonstra que o uso de muitas espécies de Asteraceae tem ajudado no progresso e sustento de grande número de povos em todo o mundo, satisfazendo suas necessidades de alimento, forragem, lenha e remédios (VITTO; PETENATTI, 2009). Muitas plantas dessa família são conhecidas pelas suas propriedades medicinais e diversas espécies possuem atividade analgésica, antiinflamatória e antimicrobiana comprovadas (LORENZI; MATOS, 2002); por produzirem compostos químicos bastante promissores, são de grande interesse para a indústria farmacêutica (ARAÚJO et al., 2008).

Na flora nativa da Caatinga, as Asteraceae estão representadas por 100 gêneros e 267 espécies, pouco mais da metade endêmica deste bioma (FORZZA et al., 2010). Várias espécies, nativas e exóticas são cultivadas como alimentícias ou ornamentais, porém o número de representantes da família utilizados pela população que habita a Caatinga ainda é pequeno, sendo necessários estudos que ampliem o número de espécies úteis, para um melhor aproveitamento da flora local. Diante disto, o presente estudo visou pesquisar o conhecimento etnobotânico da família Asteraceae compartilhado por moradores do município de Camocim de São Félix, situado no agreste pernambucano, particularmente no que se refere ao uso medicinal.

\section{Material e Métodos}

O território do município de Camocim de São Félix corresponde a $53,58 \mathrm{~km}^{2}$ e está localizado na Mesorregião Agreste e na Microrregião Brejo do Estado de Pernambuco, nos domínios da Bacia Hidrográfica do rio Sirinhaém (BELTRÃO et al., 2005). Está inserido 
na unidade geoambiental do Planalto da Borborema, a uma altitude de $691 \mathrm{~m}$, sob clima tropical chuvoso, com verão seco, e a vegetação predominante é formada por Florestas Subcaducifólias (BELTRÃO et al., 2005).

A pecuária é predominante na área, concomitantemente com a horticultura (Lycopersicum esculentum L., tomate; Capsicum annuum L., pimentão; Cucumis sativus L., pepino; Beta vulgaris var. cicla L., acelga, entre outros) e a floricultura (BARBOSA; SANTOS, 2009). No período chuvoso (abril a agosto), são cultivados, principalmente, milho (Zea mays L.), mandioca (Manihot esculenta Crantz.) e feijão (Phaseolus vulgaris L.). As hortaliças são cultivadas apenas nos meses mais secos, de setembro a março (SILVA et al., 1999).

Tropeiros que viajavam em busca de trabalho pela região onde hoje se encontra o município contribuíram para o surgimento dos primeiros povoados por volta de 1890, originando-se Camocituba, reconhecido como distrito de Bezerros em 1893; em 1953 houve a emancipação política e o novo município recebeu o nome Camocim de São Felix, devido à existência de uma igreja católica dedicada a São Félix de Cantalice no local (BARBOSA; SANTOS, 2009). Distando aproximadamente $103 \mathrm{~km}$ da capital do estado, e com uma população de 17.093 habitantes, dos quais 14.320 se concentram na área urbana (IBGE, 2010), oferece condições de atendimento médico e educacional básicos, dispondo de uma unidade de saúde e 94 salas de aula, sendo 12 da rede estadual, 61 municipais e 21 particulares (BELTRÃO et al., 2005).

O presente estudo foi realizado nas comunidades rurais Sítio Mondé dos Cabrais, Sítio Palmeira, Sítio Santa Luzia e Sítio Brejinho, localizadas na periferia do município, onde moram famílias de agricultores que trabalham na região. Para coleta dos dados etnobotânicos foram realizadas entrevistas semiestruturadas no período de dezembro de 2010 a março de 2011; os entrevistados foram abordados em suas residências, totalizando 50 moradores que concordaram em participar da pesquisa e que assinaram o termo de consentimento livre e esclarecido, como recomendado pela resolução 196/96, do Comitê de Ética em Pesquisa (MINISTÉRIO DA SAÚDE, 2002). O número amostral de 50 entrevistados foi considerado suficiente após ser verificada a curva de acumulação de espécies, que se mostrou estabilizada para o número de espécies vegetais citadas por esses informantes. Os formulários empregados nas entrevistas continham perguntas para coletas de dados socioeconômicos e dados etnobotânicos abordando todos os tipos de conhecimento sobre plantas e sua utilização, e foi realizada a técnica de turnê guiada, junto com os entrevistados, que identificaram as espécies citadas presentes na região.

Após os entrevistados citarem todas as espécies vegetais que consideravam úteis, para levantar dados sobre as Asteraceae que ocorrem na região foi empregada uma pergunta-chave: "Você conhece esta planta?" ao mesmo tempo em que foi empregada a técnica de estímulo visual (GARCIA, 2006; MONTEIRO et al., 2006a; 2006b), onde foram exibidas ao entrevistado, sempre na mesma sequência, fotos de 27 espécies de Asteraceae, retiradas em visitas prévias ao local, com flor ou fruto, todas ruderais. Quando a resposta foi afirmativa foi perguntado também se a planta tinha alguma utilização, considerando-se as seguintes etnocategorias: medicinal, alimentícia, ornamental e tecnológica. O número de citações para cada planta foi independente da forma de uso e as indicações terapêuticas citadas pelos informantes foram convertidas para o termo técnico de acordo com a Organização Mundial de Saúde (OMS).

O material botânico coletado com ajuda dos informantes foi herborizado (MORI et al., 1989) e depositado no Herbário Geraldo Mariz (UFP). Os informantes indicaram o nome vernacular local da planta e as identificações das espécies foram efetuadas através de consulta a exsicatas previamente identificadas por especialistas e depositadas no herbário UFP.

\section{Resultados e Discussão}

Como é costume na zona rural do agreste pernambucano, os homens regressam ao lar apenas no fim do dia, e não se mostraram dispostos a participar das entrevistas. Dessa forma, apenas três agricultores e um trabalhador da sementeira da comunidade, com faixa etária dos 20 aos 62 anos, concordaram em participar da pesquisa, predominando assim informações fornecidas pelas mulheres $(92 \%)$. 
A maioria dos entrevistados encontrava-se nas faixas etárias dos 31 aos 45 anos $(36 \%)$ e 46 aos 60 anos (28\%); apenas $20 \%$ são adolescentes ou jovens, entre 15 e 30 anos de idade e $16 \%$ são idosos, entre 61 e 80 anos. Considerando a origem, constatou-se que há pouca influência de culturas externas, pois, apesar da maioria ser oriunda de outros municípios, quase todos nasceram na Microrregião do Brejo: 36\% em Camocim de São Felix, 14\% em Sairé, 8\% em Bonito, 4\% em São Joaquim do Monte e $6 \%$ em Agrestina; o restante provém de municípios próximos, como Bezerros (22\%), Caruaru (22\%) e São Caetano (2\%), situados na Microrregião do Vale do Ipojuca, sendo apenas 2\% na Mesorregião do Sertão Pernambucano (Iguaracy), 2\% nascidos em Cortês, na Microrregião da Mata Meridional e 2\% na Mesorregião Recife, no litoral do estado.

A agricultura foi indicada como a ocupação de grande parte dos entrevistados, mesmo não exercendo mais a profissão. Apesar de $68 \%$ ter cursado o ensino fundamental, parte dos entrevistados afirmou saber apenas assinar o próprio nome.

A renda familiar da maioria dos entrevistados é muito baixa e apenas $10 \%$ tem o rendimento mensal maior que um salário mínimo nacional. Se for considerada a renda per capita de cada família, cerca da metade das pessoas (54\%) dispõe de apenas $\mathrm{R} \$ 100,00$ para todas as despesas mensais, o que corresponde a 1,85 dólar/dia, valor muito próximo do índice de pobreza extrema estabelecido pelo Banco Mundial (2011), cujo valor é de um dólar por dia. Essa condição é amenizada pela utilização dos recursos vegetais para suprir grande parte de suas necessidades básicas, principalmente alimentos e remédios para doenças mais corriqueiras, como parasitoses, problemas dos aparelhos digestório e respiratório.

A partir dos dados dos formulários semiestruturados, foram selecionadas as espécies de Asteraceae, juntamente com as dez espécies úteis reconhecidas através das fotografias apresentadas no momento das entrevistas (Figura 1). Foram reconhecidas, no total, 19 espécies de Asteraceae citadas como úteis; destas, pouco mais da metade tem uso medicinal (57\%), confirmando o grande potencial terapêutico da família frequentemente evidenciado em estudos etnobotânicos (Tabela 1).

\section{Acanthospermum hispidum DC.}

Espécie nativa, citada por 17 entrevistadas, com idades variando dos 30 aos 65 anos, havendo entre elas uma agente comunitária, uma cozinheira, três donasde-casa, três aposentadas e nove agricultoras, que indicaram o uso do espinho-de-cigano contra asma, tosse, inflamação na garganta, odontalgia, problemas renais, inflamações gênito-urinárias e como cicatrizante.

Albuquerque e Andrade (2002) verificaram o uso de espécies vegetais em outro município do Nordeste brasileiro, Alagoinha, onde A. hispidum também foi indicado no tratamento da tosse e da asma.

Araújo et al. (2008) revisaram a literatura sobre A. hispidum, no período de 1926-2006, nas áreas de etnobotânica, fitoquímica e farmacologia, e relataram a baixa toxicidade da espécie. Apesar de evidenciarem toxicidade das sementes ingeridas por ratos, Bakhita e Adam (1978) concluíram que os testes de toxicidade aguda, sub-aguda e crônica, em conjunto com os ensaios pré-clínicos da possível ação anti-asmática, dão suporte ao uso popular de $A$. hispidum.

\section{Acmella uliginosa (Sw.) Cass.}

Espécie nativa, conhecida na comunidade como agrião, foi indicada para o tratamento da inflamação na garganta, por uma entrevistada, cozinheira, de 65 anos, que indicou o chá das folhas, ou mastigar as inflorescências e em seguida engolir o sumo.

Ong et al. (2011) realizaram testes para avaliar a atividade antinociceptiva do extrato metanólico de A. uliginosa, o qual mostrou resposta significativa em todos os modelos químicos e de nocicepção térmica induzida; camundongos tratados com o extrato não mostraram alteração significativa de desempenho motor, nenhuma mortalidade e nem sinais de toxicidade após o tratamento.

\section{Baccharis cinerea DC.}

Trepadeira nativa e endêmica do Brasil, conhecida por cessa-furo, foi citada por uma agricultora, de 28 anos, como sendo útil no combate a tosse, enquanto 
FIGURA 1: Dez espécies da família Asteraceae reconhecidas como úteis pelos moradores de Camocim de São Félix, Pernambuco, Nordeste do Brasil. A. Acanthospermum hispidum DC.; B. Acmella uliginosa (Sw.) Cass.; C. Baccharis cinerea DC.; D. Bidens pilosa L.; E. Conocliniopsis prasiifolia (DC.) R.M. King \& H. Rob.; F. Conyza bonariensis (L.) Cronquist; G. Eclipta prostrata (L.) L.; H. Emilia sonchifolia (L.) DC.; I. Parthenium hysterophorus L.; J. Sonchus oleraceus L. Fotos: Aryêcha Arruda, janeiro a maio de 2009.

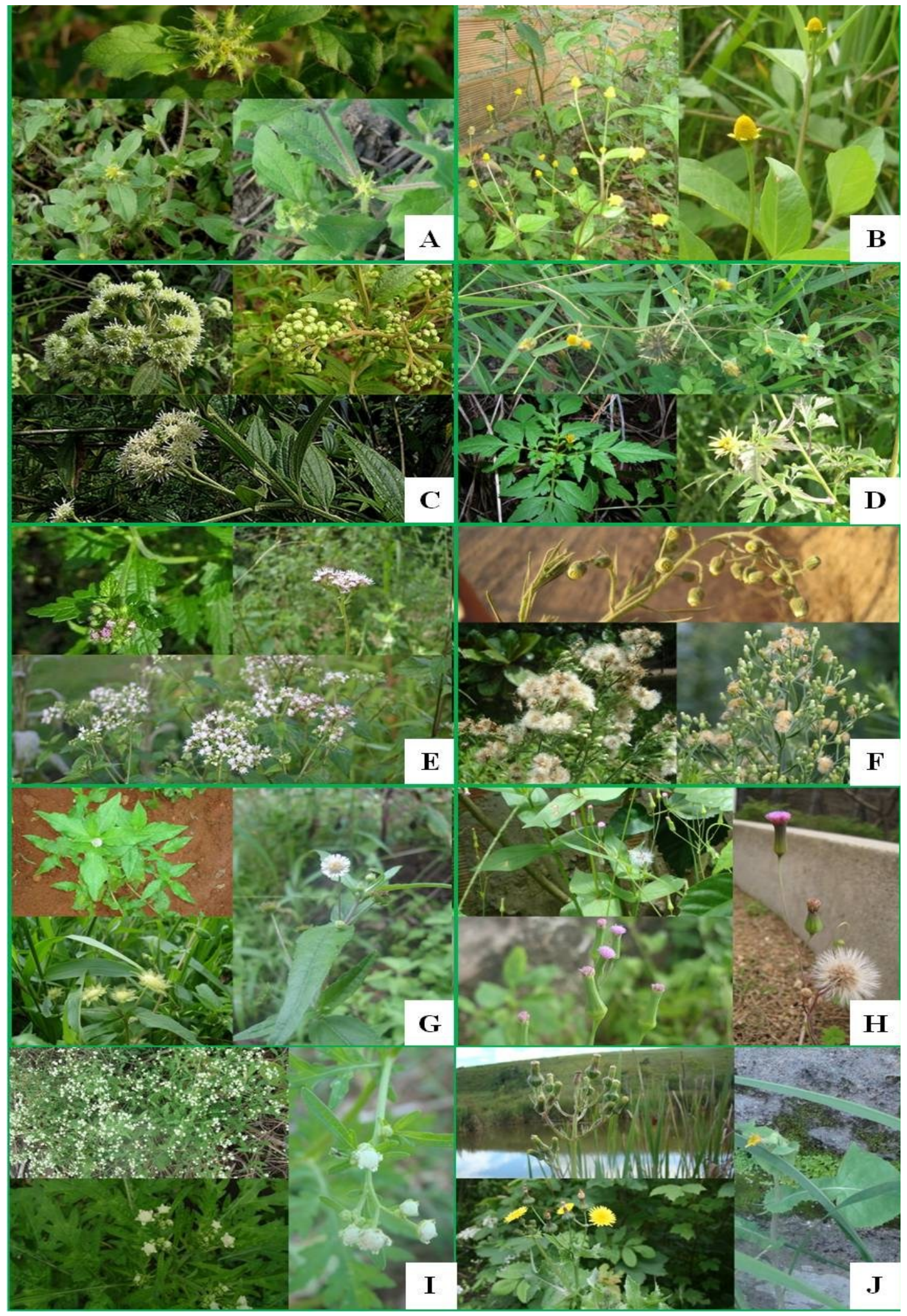


TABELA 1: Espécies de Asteraceae citadas como úteis pelos habitantes de quatro comunidades rurais de Camocim de São Félix, Pernambuco, Nordeste do Brasil. Categorias de uso: MED - Medicinal; ORN - Ornamental; TEC Tecnológica; ALI - Alimentícia. Citações independentes da forma de uso. Indicações terapêuticas citadas foram convertidas para os termos da Organização Mundial de Saúde (OMS). Partes das plantas e formas de uso indicadas pelos informantes.

\begin{tabular}{|c|c|c|c|c|c|c|}
\hline Espécie & $\begin{array}{c}\text { Nome } \\
\text { vernacular }\end{array}$ & $\begin{array}{l}\text { Categoria } \\
\text { de uso }\end{array}$ & Citações & Indicação terapêutica & $\begin{array}{l}\text { Parte da } \\
\text { planta }\end{array}$ & Forma de uso \\
\hline $\begin{array}{l}\text { Acanthospermum } \\
\text { hispidum DC. }\end{array}$ & $\begin{array}{l}\text { Espinho-de- } \\
\text { cigano }\end{array}$ & MED & 17 & $\begin{array}{l}\text { Asma, tosse, inflamação } \\
\text { na garganta, odontalgia, } \\
\text { cicatrizante, problemas } \\
\text { renais, inflamações genito- } \\
\text { urinárias }\end{array}$ & Raiz, fruto & $\begin{array}{c}\text { Chá, lambedor, } \\
\text { banho, } \\
\text { gargarejo }\end{array}$ \\
\hline $\begin{array}{l}\text { Acmella uliginosa } \\
\text { (Sw.) Cass. }\end{array}$ & Agrião & MED & 1 & Inflamação na garganta & $\begin{array}{l}\text { Folha, } \\
\text { inflorescência }\end{array}$ & $\begin{array}{l}\text { Chá, } \\
\text { mastigação }\end{array}$ \\
\hline Baccharis cinerea DC. & Cessa-furo & MED, ORN & 2 & Tosse & Folha & Chá \\
\hline Bidens pilosa $\mathrm{L}$. & $\begin{array}{l}\text { Picão, } \\
\text { evanço }\end{array}$ & MED & 3 & $\begin{array}{c}\text { Asma, inflamação, } \\
\text { dermatoses }\end{array}$ & Folha & Chá, banho \\
\hline $\begin{array}{l}\text { Conocliniopsis } \\
\text { prasiifolia (DC.) } \\
\text { R.M. King \& H. Rob. }\end{array}$ & $\begin{array}{l}\text { Mentrasto- } \\
\text { roxo }\end{array}$ & MED & 1 & $\begin{array}{l}\text { Queratose (rachadura no } \\
\text { pé) }\end{array}$ & Folha & Maceração \\
\hline $\begin{array}{l}\text { Conyza bonariensis } \\
\text { (L.) Cronquist }\end{array}$ & $\begin{array}{l}\text { Rabo-de- } \\
\text { raposa }\end{array}$ & MED, TEC & 2 & $\begin{array}{c}\text { Dermatomicose (pano- } \\
\text { branco) }\end{array}$ & $\begin{array}{l}\text { Folha, } \\
\text { inflorescência }\end{array}$ & Garrafada \\
\hline Dahlia pinnata $\mathrm{Cav}$. & Dália & ORN & 7 & - & Inflorescência & $\begin{array}{l}\text { Canteiros e } \\
\text { jardins }\end{array}$ \\
\hline $\begin{array}{l}\text { Eclipta prostrata (L.) } \\
\text { L. }\end{array}$ & Vamora & MED & 2 & Gripe, hematoma & Folha & $\begin{array}{l}\text { Lambedor, } \\
\text { tópico }\end{array}$ \\
\hline Egletes viscosa Less. & Macela & TEC & 1 & - & Inflorescência & $\begin{array}{l}\text { Travesseiros } \\
\text { artesanais }\end{array}$ \\
\hline $\begin{array}{l}\text { Emilia sonchifolia } \\
\text { (L.) DC. }\end{array}$ & Emilia & ALI & 1 & - & Folha & Mastigação \\
\hline Helianthus annuиs L. & Girassol & MED & 1 & Epilepsia & Semente & Chá \\
\hline Lactuca sativa $\mathrm{L}$. & Alface & ALI & 22 & - & Folha & Salada \\
\hline $\begin{array}{l}\text { Leucanthemum } \\
\text { vulgare Tourn. ex } \\
\text { Lam. }\end{array}$ & Margarida & ORN & 2 & - & Inflorescência & $\begin{array}{l}\text { Canteiros e } \\
\text { jardins }\end{array}$ \\
\hline Matricaria recutita $\mathrm{L}$. & Camomila & MED & 5 & Calmante & $\begin{array}{l}\text { Folha, } \\
\text { inflorescência }\end{array}$ & Chá \\
\hline $\begin{array}{l}\text { Parthenium } \\
\text { hysterophorus L. }\end{array}$ & $\begin{array}{l}\text { Vassourinha- } \\
\text { de-relógio }\end{array}$ & TEC & 12 & - & Planta toda & Varrer \\
\hline Sonchus oleraceus L. & $\begin{array}{l}\text { Gogo-de- } \\
\text { ema }\end{array}$ & MED & 2 & $\begin{array}{c}\text { Tosse, queilite angular } \\
\text { (boqueira) }\end{array}$ & Raiz, látex & $\begin{array}{l}\text { Lambedor, uso } \\
\text { direto }\end{array}$ \\
\hline Tagetes erecta $\mathrm{L}$. & $\begin{array}{l}\text { Cravo- } \\
\text { branco, } \\
\text { cravo-de- } \\
\text { defunto }\end{array}$ & MED, ORN & 1 & Calmante & Inflorescência & Chá \\
\hline $\begin{array}{l}\text { Vernonanthura } \\
\text { condensata (Baker) } \\
\text { H. Rob. }\end{array}$ & Alcachofra & MED & 7 & $\begin{array}{c}\text { Problemas hepáticos, } \\
\text { enjôo, problemas } \\
\text { digestivos }\end{array}$ & Folha & Chá \\
\hline Zinnia elegans Jacq. & Benedita & ORN & 1 & 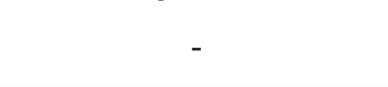 & Inflorescência & $\begin{array}{c}\text { Canteiros e } \\
\text { jardins }\end{array}$ \\
\hline
\end{tabular}


que uma aposentada, de 65 anos, informou utilizá-la na ornamentação de jardins.

Seu sinônimo, Baccharis trinervis Pers., foi citado como medicinal em trabalhos como o de Abad et al. (1999), que descreveram a atividade antiviral do extrato de $B$. cinerea, que inibiu em $100 \%$ a replicação do vírus de herpes simples tipo I (HVS-1). Citada para o tratamento de mordidas de serpentes, dor de estômago, como anti-séptico em infecções de pele e feridas, câimbras musculares, edemas, lactogênico, dores renais, inflamações, diarreia, reumatismo, dores no corpo, enfermidades hepáticas, combater febre tifoide, hemorroidas, assim como para impotência sexual e esterilidade feminina, além de permitir a evacuação de cálculos biliares e é usada como purgante (MORTON, 1981; TORRES, 1995).

\section{Bidens pilosa L.}

Espécie subespontânea, conhecida por picão ou evanço, foi citada por uma aposentada e duas agricultoras, com 35, 64 e 65 anos, que a indicaram para combater a asma, inflamações e problemas na pele, como dermatoses e alergias.

Bidens pilosa recebe diferentes nomes no Brasil, como cabeludo no Centro-Oeste, carrapicho-de-agulha no Nordeste, picão-da-praia no Sudeste e pico-pico no Sul, com indicações para o tratamento de malária, problemas hepáticos, diabetes, gonorreia, gases estomacais, disenteria, erisipela, problemas renais, hepatite, icterícia, hemorroida, reumatismo articular, alergia, anemia, brotoeja e como vermífugo (CASTELLUCCI et al., 2000; RODRIGUES; CARVALHO, 2001; MOREIRA et al., 2002; MEDEIROS et al., 2004; LIMA; SANTOS, 2006; SOUZA; FELFILI, 2006; NEGRELLE; FORNAZZARI, 2007; PEREIRA et al., 2009; SOUZA et al., 2010).

Em Porto Alegre (RS), Vendrusculo e Mentz (2006) verificaram que $B$. pilosa, conhecida popularmente por picão, foi indicada como antibiótico, anti-inflamatório, contra a congestão nasal, para afecções da garganta, infecção e inflamação nos ovários. Silva et al. (2009), em Indaial (SC), constataram que esta espécie, também conhecida como picão, era indicada como anti-inflamatório, analgésico, antiartereosclerose e antirreumático.

\section{Conocliniopsis prasiifolia (DC.) R.M.} King \& H. Rob.

O uso tópico das folhas in natura desta espécie, nativa do Brasil, conhecida como mentrasto-roxo, foi relatado por apenas uma entrevistada, aposentada, de 52 anos, que a indicou para o tratamento de queratose, localmente denominada rachaduras dos pés. Este tipo de problema é ocasionado por fatores externos, como lesões provocadas por atrito com o solo (andar descalço) ou com calçados inadequados, ou internos, como falta de hidratação da pele ou envelhecimento natural do indivíduo, e não é relatado em outros estudos realizados junto a comunidades nordestinas.

Na sinopse de plantas conhecidas como medicinais e venenosas no Nordeste do Brasil, o chá das folhas desta espécie, citada como aleluia, é indicado para gripes e resfriados (AGRA et al., 2007).

Silva et al. (2005) investigaram a atividade biológica de folhas de C. prasiifolia coletadas na Paraíba e verificaram que o extrato etanólico apresenta efeito analgésico central e anti-inflamatório, com toxicidade aguda negativa.

\section{Conyza bonariensis (L.) Cronquist}

Espécie nativa, conhecida na região como rabode-raposa, foi citada apenas por uma das entrevistadas, dona de casa, com 36 anos de idade, que a indicou para tratamento da micose superficial popularmente denominada pano-branco. Em Pernambuco, é também indicada como anti-séptica e para problemas oftalmológicos (TEIXEIRA; MELO, 2006).

A atividade antifúngica desta espécie é confirmada por Lima (1996), que demonstrou a atividade do óleo essencial, oriundo de toda a planta, sobre dermatófitos isolados de lesões de pacientes, inibindo o crescimento de $76 \%$ das 16 cepas testadas.

O uso tecnológico do rabo-de-raposa foi relatado apenas por uma agricultora, de 35 anos, que afirmou utilizar a planta toda como vassoura, para varrer a parte 
externa da casa, de modo semelhante ao que fazem com a vassourinha-de-botão (Borreria verticillata $\mathrm{G}$. Meyer, Rubiaceae).

\section{Dahlia pinnata Cav.}

A dália, espécie exótica e cultivada, foi a mais citada entre as plantas ornamentais, por sete mulheres, dentre elas donas-de-casa, aposentadas e agricultoras, com idades de 20 a 75 anos, que a utilizam no adorno de seus jardins.

\section{Eclipta prostrata (L.) L.}

Espécie nativa, conhecida como vamora, foi citada por duas agricultoras (28 e 34 anos), que indicaram o uso de suas folhas como xarope (lambedor) para tratamento de gripe e como compressa morna em traumatismos causados por quedas ou pancadas (hematomas).

Esta espécie é muito citada como medicinal em inventários etnobotânicos e etnofarmacológicos, popularmente indicada para combater a gripe.

\section{Egletes viscosa Less.}

Espécie nativa que foi indicada por uma agricultora de 35 anos, que informou utilizar as inflorescências da macela na confecção de travesseiros artesanais, por causa do seu odor agradável.

Estudos desenvolvidos em outras comunidades nordestinas, como Alagoinha (PE) e Juazeiro (BA), indicaram sua utilização como medicinal no combate a problemas digestivos e estomacais (ALBUQUERQUE; ANDRADE, 2002; GOMES et al., 2008).

\section{Emilia sonchifolia (L.) DC.}

A emilia, espécie nativa, foi citada como comestível por uma dona-de-casa de 60 anos, que informou serem as folhas utilizadas em saladas.

A espécie é também conhecida em outras regiões do país como vassourinha, falsa-serralha, bela-emilia, pincel e serralhinha. Estudo realizado em Jupi (PE) indicou seu uso medicinal para emagrecer, usando o chá de suas folhas (TEIXEIRA; MELO, 2006).

\section{Helianthus annuus L.}

O girassol, espécie exótica e cultivada, foi indicado por uma aposentada de 54 anos, que a citou como útil no controle da epilepsia, utilizando o chá de suas cipselas. Esta espécie foi citada por comerciantes de feiras livres do Vale do São Francisco e por moradores do município de Jupi (PE) como analgésica (TEIXEIRA; MELO, 2006; GOMES et al., 2008).

\section{Lactuca sativa L.}

A alface, espécie exótica e cultivada, foi a mais citada (22), mencionada por um agricultor de 51 anos e 21 mulheres com diferentes atividades (agricultoras, aposentadas, donas-de-casa, agente comunitária, estudante e cozinheira), com idades de 15 a 70 anos. Todos os informantes citaram a alface como espécie alimentícia, utilizada em saladas e cultivada na região.

Estudos realizados em Jataí (SP) e Jupi (PE) mostraram que o chá de suas folhas ou broto é popularmente utilizado como calmante (CASTELLUCCI et al., 2000; TEIXEIRA; MELO, 2006).

\section{Leucanthemum vulgare Tourn. ex Lam.}

A margarida, espécie exótica e cultivada, foi citada como ornamental por uma estudante (15 anos) e uma agricultora (37 anos).

\section{Matricaria recutita L.}

A camomila, uma espécie exótica, foi indicada como calmante por quatro agricultoras e uma dona-decasa, com idades de 43 a 65 anos, que adquirem suas inflorescências através do comércio em feiras livres.

Esta mesma indicação pode ser verificada em diversas regiões do país, como em Jupi, agreste de Pernambuco, Natal e Santa Cruz, nas regiões litorâneas e agreste do Rio Grande do Norte, e Indaial, no vale do Itajaí em Santa Catarina (TEIXEIRA; MELO, 2006; MOSCA; LOIOLA, 2009; SILVA et al., 2009). Em Ponta Porã (MS), ela ainda pode ser usada como anti-séptico, anti-inflamatório, irritação na garganta, nos olhos, para problemas digestivos e cólicas intestinais (PEREIRA et al., 2009). 


\section{Parthenium hysterophorus L.}

A vassourinha-de-relógio, espécie subespontânea, foi citada por 12 entrevistadas, entre elas agentes de saúde, agricultoras, donas-de-casa e aposentadas, com idade entre 20 e 75 anos, como sendo utilizada na confecção de vassouras naturais, para varrer os arredores das casas.

\section{Sonchus oleraceus L.}

Espécie nativa, citada por uma dona-de-casa, 42 anos, e uma agricultora, 64 anos, indicada contra tosse e dermatomicose conhecida na comunidade como boqueira, que corresponde à queilite angular caracterizada por inflamação, fissuração e maceração dos ângulos da boca.

Em Jataí (SP), Castellucci et al. (2000) verificaram que $S$. oleraceus, conhecida por serralha, foi indicada contra úlceras e anemia, enquanto que Vendrusculo e Mentez (2006) constataram que em Porto Alegre (RS), a espécie era conhecida como dente-de-leão e serralha, e indicada como antibiótico, antiinflamatório, no combate a diabete, e contra problemas digestivos, além de ser incluída na alimentação, em saladas.

Al-Hussaini e Mahasneh (2011) avaliaram a atividade antibacteriana e antifúngica da parte aérea de exemplares colhidos na Jordânia e informam que o extrato etanólico mostrou moderada atividade contra bactérias gram-negativas, gram-positivas e fungos patogênicos filamentosos e não filamentosos.

Lima et al. (2009) realizaram a prospecção fitoquímica de $S$. oleraceus e sua toxicidade sobre o microcrustáceo Artemia salina e verificaram a ocorrência de saponinas e derivados terpênicos e esteroidais no extrato diclorometano. Os extratos aquoso e etanólico apresentaram açúcares redutores, compostos fenólicos, taninos, flavanoides e cumarinas, com exceção de cumarinas no etanólico. Já a fitotoxicidade em $A$. salina indicou baixa toxicidade do extrato-teste.

\section{Tagetes erecta L.}

O cravo-branco ou cravo-de-defunto, espécie subespontânea, foi citado por uma aposentada de 76 anos como calmante e por uma dona-de-casa e uma agricultora, de 42 e 46 anos, como ornamental.

Em Jupi (PE), ela foi citada contra cardiopatias (TEIXEIRA; MELO, 2006). Estudos mostraram que T. erecta contém luteína, que possui ação antioxidante, reduz a degeneração muscular, além de inibir a atividade mutagênica (CHEW et al., 1996; MEJÍA et al., 1997; ALVES-RODRIGUES; SHAO, 2004). Marques et al. (2011) avaliaram a atividade do óleo essencial de $T$. erecta contra o Aedes aegypti, que foi ativo contra as larvas do mosquito, sendo mais eficientes se extraídos das raízes e flores.

\section{Vernonanthura condensata (Baker) H. Rob.}

Uma espécie nativa, conhecida localmente por alcachofra, foi indicada por seis mulheres (duas aposentadas, duas donas-de-casa, uma agricultora e uma estudante), com idade variando de 15 a 75 anos, e um homem, agricultor de 47 anos, que indicaram para o tratamento de problemas hepáticos, enjoos e problemas digestivos.

Recebe muitos nomes populares, conforme a região do país, como alcachofra, alumã e boldo-branco no nordeste, figatíl e sacaca no norte, boldo-folha-nina, assa-peixe e boldo-do-chile no sudeste e figatíl e boldo no sul. Em Ilhéus, na Bahia, esta espécie, conhecida localmente por alumã, é indicada para tratar de problemas digestivos e febres (MOREIRA et al., 2002). No norte, em Rondônia, Lima e Santos (2006) verificaram seu uso para tratar de problemas hepáticos. No sudeste, no Rio de Janeiro, Fonseca-Kruel e Peixoto (2004) verificaram que $V$. condensata (citada como Vernonia condensata Baker) foi indicada no tratamento de problemas digestivos. Pode ainda ser usada no tratamento de anemia, ferimentos, gripe e bronquite, insônia, micoses, no controle da glicose e no asseio vaginal (MEDEIROS et al., 2004; MARTINS et al., 2005; TEIXEIRA; MELO, 2006; NEGRELLE; FORNAZZARI, 2007).

Risso et al. (2010) avaliaram a toxicidade aguda e o efeito antinociceptivo das folhas de V. condensata (citada como Vernonia condensata), e constataram que seus diferentes extratos mostraram efeito antinociceptivo, 
porém concluíram que o extrato utilizado influencia tanto a atividade farmacológica, quanto a toxicidade aguda das folhas.

\section{Zinnia elegans Jacq.}

A benedita, uma espécie subespontânea, foi citada por uma aposentada de 60 anos, que a utiliza na ornamentação do jardim.

Carneiro et al. (2002) referem que a espécie é utilizada principalmente em paisagismo como bordaduras e maciços florais; também se destaca entre as espécies de maior potencial de cultivo para flor de corte em vasos e visando a ornamentação (MENEZES et al., 2008).

A quantidade de espécies da família Asteraceae encontrada neste estudo pode ser considerada alta se comparada com pesquisas desenvolvidas no país. Santos et al. (2009) estudaram as espécies úteis em áreas antropogênicas em uma comunidade rural de Altinho, agreste de Pernambuco, onde foram identificadas 79 espécies úteis distribuídas em 28 famílias. A família Asteraceae foi a terceira em número de espécies (8), e apenas Acanthospermum hispidum DC. coincidiu com o estudo em Camocim de São Félix, indicada como medicinal e forragem.

Miranda e Hanazaki (2008) investigaram a etnobotânica de comunidades litorâneas das Ilhas do Cardoso (SP) e de Santa Catarina (SC) para fins alimentares, medicinais e manufatureiros quanto ao conhecimento e uso dos recursos vegetais locais, onde as famílias botânicas com maior número de espécies foram Myrtaceae (25 espécies); Asteraceae (18 espécies) e Poaceae (17 espécies). Christo et al. (2006) reuniram informações sobre uso de plantas numa comunidade rural em Silva Jardim (RJ) onde foram obtidas 549 citações de uso de 210 espécies, subordinadas a 74 famílias. Asteraceae, Leguminosae, Lamiaceae, Euphorbiaceae, Myrtaceae e Poaceae apresentam maiores riquezas distribuídas nas categorias alimentação, medicinal, construção, combustível, ornamental, ritualística, tecnologia, tóxica e veterinária.

Amaral e Guarim (2007) estudaram as plantas utilizadas pelos moradores da comunidade de Cascavel,
Jangada (MT) onde foram relacionadas 111 espécies vegetais, pertencentes a 97 gêneros e 48 famílias botânicas e a família Asteraceae foi a mais representativa, possuindo $11 \%$ das espécies citadas e Lamiaceae 5\%.

As comunidades rurais de Camocim de São Félix consideram úteis várias espécies da família Asteraceae, principalmente para o tratamento de doenças, embora elas também sejam úteis na alimentação, na ornamentação e na tecnologia. Esse conhecimento é oriundo de uma cultura de uso dos recursos vegetais, muitas vezes necessária para subsistência das famílias mais carentes.

\section{Agradecimentos}

Aos moradores de Camocim de São Félix, pela atenção e interesse em participar da pesquisa; ao Programa de Pós-graduação em Biologia Vegetal (PPGBV/UFPE) e à Coordenação de Aperfeiçoamento de Pessoal de Nível Superior (CAPES), pelo apoio financeiro.

\section{Referências}

ABAD, M. J.; BERMEJO, P.; PALOMINO, S. S.; CHIRIBOGA, X.; CARRASCO, L. Antiviral activity of some South American medicinal plants. Phytotherapy Research, London, v. 13, p. 142146, 1999.

AGRA, M. F.; FREITAS, P. F.; BARBOSA-FILHO, J. M. Synopsis of the plants known as medicinal and poisonous in Northeast of Brazil. Revista Brasileira de Farmacognosia, Curitiba, v. 17, n.1, p. 114-140, 2007.

ALBUQUeRQuE, U. P.; ANDRADE, L. H. C. Conhecimento botânico tradicional e conservação em uma área de caatinga no Estado de Pernambuco, Nordeste do Brasil. Acta Botanica Brasilica, Feira de Santana, v. 16, n. 3, p. 273-285, 2002.

ALVES-RODRIGUES, A.; SHAO, A. The science behind lutein. Toxicology Letters, Clare, v. 150, p. 57-83, 2004.

AL-HUSSAINI, R.; MAHASNEH, A. M. Antibacterial and antifungal activity of ethanol extract of different parts of medicinal plants in Jordan. Jordan Journal of Pharmaceutical Sciences, Amman, v. 4, n. 1, p. 57-68, 2011.

AMARAL, C. N.; GUARIM, V. L. M. S. Estudo etnobotânico da comunidade rural de Cascavel (Jangada - MT). Revista Brasileira de Biociências, Porto Alegre, v. 5, n. 1, p. 894-896, 2007.

ARAÚJO, E. L.; RANDAU, K. P.; SENA-FILHO, J. G.; PIMENTEL, R. M. M.; XAVIER, H. S. Acanthospermum hispidum DC (Asteraceae): perspectives for a phytotherapeutic product. Revista Brasileira de Farmacognosia, Curitiba, v. 18, p. 777-784, 2008. 
BAKHITA, A.; ADAM, S. E. I. Effects of Acanthospermum hispidum on goats. Journal of Comparative Pathology, London, v. 88, p. 533-544, 1978.

BANCO MUNDIAL. Relatório sobre o desenvolvimento mundial 2000/2001. Luta contra a pobreza. Washington: Panorama Geral Banco Mundial, 2001.

BARBOSA, A. D.; SANTOS, M. R. A nova funcionalidade da agricultura no brejo de Camocim de São Félix. In: ENCONTRO NACIONAL DE GEOGRAFIA AGRÁRIA, 19, 2009, São Paulo. Anais... São Paulo: ENGA, 2009. p. 1-26.

BELTRÃO, B. A; MASCARENHAS, J. C.; MIRANDA, J. L. F.; SOUZA JUNIOR, L. C.; GALVÃO, M. J. T. G.; PEREIRA, S. N. Diagnóstico do município de Camocim de São Félix. Projeto cadastro de fontes de abastecimento por água subterrânea do Estado de Pernambuco. Recife: CPRM/PRODECEEM, 2005. 20 p.

CARNEIRO, T. F.; FINGER, F. L.; SANTOS, V. R.; NEVES, L. L. M.; BARBOSA, J. G. Influência da sacarose e do corte da base da haste na longevidade de inflorescências de Zinnia elegans. Pesquisa Agropecuária Brasileira, v. 37, n. 8, p. 1065-1070. 2002. CASTELLUCCI, S.; LIMA, M. I. S.; NORDI, N.; MARQUES, J. G. W. Plantas medicinais relatadas pela comunidade residente na Estação Ecológica de Jataí, Município de Luís Antonio/SP: uma abordagem etnobotânica. Revista Brasileira de Plantas Medicinais, Botucatu, v. 3, n. 1, p. 51-60, 2000.

CHEW, B. P.; WONG, M. W.; WONG, T. S. Effects of lutein from marigold extract on immunity and growth of mammary tumors in mice. Anticancer Research, Kapandriti, v. 16, p. 3689-3694, 1996. CHRISTO, A. G.; GUEDES-BRUNI, R. R.; FONSECA-KRUEL, V. S. Uso de recursos vegetais em comunidades rurais limítrofes à Reserva Biológica de Poço das Antas, Silva Jardim, Rio de Janeiro: estudo de caso na Gleba Aldeia Velha. Rodriguesia, Rio de Janeiro, v. 57, n. 3, p. 519-542, 2006.

FONSECA-KRUEL, V. S.; PEIXOTO, A. L. Etnobotânica na Reserva Extrativista Marinha de Arraial do Cabo, RJ, Brasil. Acta Botanica Brasilica, Feira de Santana, v. 18, n. 1, p. 177-190, 2004. FORZZA, R. C.; LEITMAN, P. M.; COSTA, A. F.; CARVALHO JR., A. A.; PEIXOTO, A. L.; WALTER, B. M. T.; BICUDO, C.; ZAPPI, D.; COSTA, D. P.; LLERAS, E.; MARTINELLI, G.; LIMA, H. C.; PRADO, J.; STEHMANN, J. R.; BAUMGRATZ, J. F. A.; PIRANI, J. R.; SYLVESTRE, L.; MAIA, L. C.; LOHMANN, L. G.; QUEIROZ, L. P.; SILVEIRA, M.; COELHO, M. N.; MAMEDE, M. C.; BASTOS, M. N. C.; MORIM, M. P.; BARBOSA, M. R.; MENEZES, M.; HOPKINS, M.; SECCO, R.; CAVALCANTI, T. B.; SOUZA, V. C. 2010. Lista de espécies da flora do Brasil. Rio de Janeiro: Jardim Botânico do Rio de Janeiro. Disponível em: <http:// floradobrasil.jbrj.gov.br/2012/>. Acesso em: 15 jan. 2012.

GARCIA, G. F. C. The mother - child nexus. Knowledge and valuation of wild food plants in Wayanad, Western Ghats, India. Journal of Ethnobiology and Ethnomedicine, London, v. 2, n. 39, p. 1-6, 2006.

GOMES, E. C. S.; BARBOSA, J.; VILAR, F. C. R.; PEREZ, J. O.; VILAR, C. R.; FREIRE, J. L. O.; LIMA, A. N.; DIAS, T. J. Plantas da caatinga de uso terapêutico: levantamento etnobotânico. Engenharia Ambiental, Espírito Santo do Pinhal, v. 5, n. 2, p. 7485, 2008.

HIND, D. J. N. Notes on the Compositae of Bahia, Brasil. Kew Bulletin, Kew, v. 48, n. 2, p. 245-277, 1993.
IBGE - INSTITUTO BRASILEIRO DE GEOGRAFIA E ESTATÍSTICA. IBGE Censo 2010. 2010. Disponível em: <http:// Www.censo2010.ibge.gov.br/>. Acesso em: 15 abr. 2011.

LIMA, E. O. Estudo das dermatofitoses em João Pessoa Paraíba e da atividade antifúngica de plantas medicinais da região contra alguns dos agentes isolados. 1996. $180 \mathrm{f}$. Tese (Doutorado em Farmácia) - Universidade de São Paulo, São Paulo. 1996.

LIMA, J. M.; SILVA, C. A.; ROSA, M. B.; SANTOS, J. B.; OLIVEIRA, T. G.; SILVA, M. B. Prospecção fitoquímica de Sonchus oleraceus e sua toxicidade sobre o microcrustáceo Artemia salina. Planta Daninha, v. 27, n. 1, p. 7-11. 2009.

LIMA, M. R.; SANTOS, M. R. A. Aspectos etnobotânicos da medicina popular no Município de Buritis, Rondônia. Revista Fitos, São Paulo, v. 2, n. 2, p. 36-41, 2006.

LORENZI, H.; MATOS, F. J. A. Plantas medicinais no Brasil: nativas e exóticas. 2 ed. Nova Odessa: Instituto Plantarum. 2002. $544 \mathrm{p}$.

MARQUES, M. M. M.; MORAIS, S. M.; VIEIRA, I. G. P.; VIEIRA, M. G. S.; SILVA, A. R. A.; ALMEIDA, R. R.; GUEDES, M. I. F. Larvicidal activity of Tagetes erecta against Aedes aegypti. Journal of the American Mosquito Control Association, Washington, v. 27, n. 2, p. 156-158, 2011.

MARTINS, A. G.; ROSÁRIO, D. L.; BARROS, M. N.; JARDIM, M. A. G. Levantamento etnobotânico de plantas medicinais, alimentares e tóxicas da Ilha do Combu, Município de Belém, Estado do Pará, Brasil. Revista Brasileira de Farmacologia, São Paulo, v. 86, n. 1, p. 21-30, 2005.

MEDEIROS, M. F. T.; FONSECA, V. S.; ANDREATA, R. H. P. Plantas medicinais e seus usos pelos sitiantes da Reserva Rio das Pedras, Mangaratiba, RJ, Brasil. Acta Botanica Brasilica, Feira de Santana, v. 18, n. 2, p. 391-399, 2004.

MEJÍA, E. G.; LOARCA-PINA, G.; RAMOS-GÓMEZ, M. Antimutagenicity of xanthophylls in Aztec Marigold (Tagetes erecta) against 1-nitropyrene. Mutation Research, Amsterdam, v. 389, p. 219-226, 1997.

MENEZES, V. O.; PEDROSO, D. C.; MUNIZ, M. F. B.; BELLÉ, R.; BLUME, E.; GARCIA, D. C. Envelhecimento acelerado em sementes de Zinnia elegans Jacq. colhidas em diferentes épocas. Revista Brasileira de Sementes, Londrina, v. 30, n. 3, p. 039-047, 2008.

MINISTÉRIO DA SAÚDE. Manual operacional para comitês de ética em pesquisa. Brasília: Conselho Nacional de Saúde, 2002.

MIRANDA, T. M.; HANAZAKI, N. Conhecimento e uso de recursos vegetais de restinga por comunidades das ilhas do Cardoso (SP) e de Santa Catarina (SC), Brasil. Acta Botanica Brasilica, Feira de Santana, v. 22, n. 1, p. 203-215, 2008.

MONTEIRO, J. M.; ALBUQUERQUE, U. P.; LINS-NETO, E. M. F.; ARAÚJO, E. L.; AMORIM, E. L. C. Use patterns and knowledge of medicinal species among two rural communities in Brazil's semi-arid northeastern region. Journal of Ethnopharmacology, Shannon, v. 105, p. 173-186, 2006 a.

MONTEIRO, J. M.; ALMEIDA, C. F. C. B. R.; ALBUQUERQUE, U. P.; LUCENA, R. F. P.; FLORENTINO, A. T. N.; OLIVEIRA, R. L. C. Use and traditional management of Anadenanthera colubrina (Vell.) Brenan in the semi-arid region of northeastern Brazil. Journal of Ethnobiology and Ethnomedicine, London v. 2, n. 6, p. 1-18, 2006b. 
MOREIRA, R. C. T.; COSTA, L. C. B.; COSTA, R. C. S.; ROCHA, E. A. Abordagem etnobotânica acerca do uso de plantas medicinais na Vila Cachoeira, Ilhéus, Bahia, Brasil. Acta Farmacéutica Bonaerense, Buenos Aires, v. 21, n. 3, p. 205-211, 2002.

MORI, S. A.; SILVA, L. A. M.; LISBOA, G.; CORADIN, L. Manual de manejo do herbário fanerogâmico. Ilhéus: Centro de Pesquisa do Cacau, 1989. 97 p.

MORTON, J. F. Atlas of medicinal plants of middle America: Bahamas to Yucatan. Springfield: Charles C. Thomas Publisher, 1981. $1420 \mathrm{p}$.

MOSCA, P. V.; LOIOLA, M. I. B. Uso popular de plantas medicinais no Rio Grande do Norte, Nordeste do Brasil. Revista Caatinga, Mossoró, v. 22, n. 4, p. 225-234, 2009.

NEGRELLE, R. R. B.; FORNAZZARI, K. R. C. 2007. Estudo etnobotânico em duas comunidades rurais (Limeira e Ribeirão Grande) de Guaratuba (Paraná, Brasil). Revista Brasileira de Plantas Medicinais, Botucatu, v. 9, n. 2, p. 36-54, 2007

ONG, H. M.; MOHAMAD, A. S.; MAKHTAR, N. A.; MOHAMAD, H. K.; KHALID, S.; PERIMAL, E. K.; MASTUKI, S. N.; ZAKARIA, Z. A.; LAJIS, N.; ISRAF, D. A.; SULAIMAN, M. R. Antinociceptive activity of methanolic extract of Acmella uliginosa (Sw.) Cass. Journal of Ethnopharmacology, Shannon, v. 133 , p. $227-233,2011$

PEREIRA, R. C. A. Revisão taxonômica do gênero Ichthyothere Mart. (Heleiantheae - Asteraceae). 2001. 223 f. Tese (Doutorado em Botânica) - Universidade Federal Rural de Pernambuco, Recife. 2001

PEREIRA, R. C. A. Revisão taxonômica do gênero Ichthyothere Mart. (Heleiantheae-Asteraceae). Tese (Doutorado em Botânica) - Universidade Federal Rural de Pernambuco. 2001. 223 p.

PEREIRA, Z. V.; MUSSURY, R. M.; ALMEIDA, A. B.; SANGALLI, A. Medicinal plants used by Ponta Porã community, Mato Grosso do Sul State. Acta Scientiarum. Biological Sciences, Maringá, v. 31, n. 3, p. 293-299, 2009.

RISSO, W. E.; SCARMINIO, I. S.; MOREIRA, E. G. Antinociceptive and acute toxicity evalution of Vernonia condensata Baker leaves extracted with different solvents and their mixtures. Indian Journal of Experimental Biology, Varanasi, v. 48, p. 811-816, 2010.

RODRIGUES, V. E. G.; CARVALHO, D. A. Levantamento etnobotânico de plantas medicinais no domínio do Cerrado na região do Alto Rio Grande - Minas Gerais. Ciência \& Agrotecnologia, Lavras, v. 25, n. 1, p. 102-123, 2001.

SANTOS, L. L.; RAMOS, M. A.; SILVA, S. I.; SALES, M. F.; ALBUQUERQUE, U. P. Caatinga ethnobotany: anthropogenic landscape modification and useful species in Brazil's Semi-Arid Northeast. Economic Botany, New York, v. 63, n. 4, p. 363-374, 2009.
SILVA, A. B.; REZENDE, S. B.; SOUZA, A. R.; RESENDE, M.; LEITE, A. P. Uso de agrotóxicos no sistema de produção de hortaliças no município de Camocim de São Félix, Pernambuco. Rio de Janeiro: Embrapa Solos. Boletim de Pesquisa, 6, 1999. 22 p. SILVA, M. D.; DREVECK, S.; ZENI, A. L. B. Estudo etnobotânico de plantas medicinais utilizadas pela população rural no entorno do Parque Nacional da Serra do Itajaí - Indaial. Revista Saúde e Ambiente, Joinville, v. 10, n. 2, p. 54-64, 2009.

SILVA, M. G.; OLIVEIRA, F. S.; QUINTANS-JÚNIOR, L. J.; OLIVEIRA, T. M. L.; DINIZ, F. F. M. Investigação do efeito analgésico central e antiinflamatório de Conocliniopsis prasiifolia (DC) R. M. King \& H. Robinson em Roedores. Acta Farmacéutica Bonaerense, Buenos Aires, v. 24, n. 4, p. 533-537, 2005.

SOUZA, C. D.; FELFILI, J. M. Uso de plantas medicinais na região de Alto Paraíso de Goiás, GO, Brasil. Acta Botanica Brasilica, Feira de Santana, v. 20, n. 1, p. 135-142, 2006.

SOUZA, M. J. M.; MORAL, F. F.; NASCIMENTO, G. N. L.; SOARES, N. P; AVERSI-FERREIRA, T. A. Medicinal plants used by Itamaraty community nearby Anápolis, Goiás State, Brazil. Acta Scientiarum. Biological Sciences, Maringá, v. 32, n. 2, p. 177-184, 2010.

SOUZA, V. C.; LORENZI, H. Botânica sistemática: guia ilustrado para identificação das famílias de Fanerógamas nativas e exóticas no Brasil, baseado em APG II. 2. ed. Nova Odessa: Instituto Plantarum, 2008. 704 p.

STEVENS, P. F. Angiosperm Phylogeny Website. 2012. Disponível em: <http://www.mobot.org/MOBOT/research/ APweb/>. Acesso em: 9 dez. 2012.

TEIXEIRA, S. A.; MELO, J. I. M. Plantas medicinais utilizadas no município de Jupi, Pernambuco, Brasil. Iheringia, Série Botânica, Porto Alegre, v. 61, n. 1-2, p. 5-11, 2006.

TORRES. Plantas Medicinales Comunes de Honduras. P.R. House et al. 1. ed. Honduras. Litografía López S. de R. L. 1995. $555 \mathrm{p}$.

VENDRUSCOLO, G. S.; MENTZ, L. A. Levantamento etnobotânico das plantas utilizadas como medicinais por moradores do bairro Ponta Grossa, Porto Alegre, Rio Grande do Sul, Brasil. Iheringia, Série Botânica, Porto Alegre, v. 61, n. 1-2, p. 83-103, 2006.

VITTO, L. A.; PETENATTI, E. M. Asteráceas de importancia económica y ambiental. Primera parte. Sinopsis morfológica y taxonómica, importancia ecológica y plantas de interés industrial. Multequina, Mendoza, v. 18, p. 87-115, 2009. 